\title{
DÜBLIN
}

Technological University Dublin

ARROW@TU Dublin

2007-01-01

\section{Spline Based Geometry for Printed UWB Antenna Design}

\author{
Matthias John \\ Technological University Dublin, matthias.john@tudublin.ie \\ Max Ammann \\ Technological University Dublin, max.ammann@tudublin.ie
}

Follow this and additional works at: https://arrow.tudublin.ie/engschececon

Part of the Electrical and Computer Engineering Commons

\section{Recommended Citation APS.2007.4395605 \\ This Conference Paper is brought to you for free and open access by the School of Electrical and Electronic Engineering at ARROW@TU Dublin. It has been accepted for inclusion in Conference papers by an authorized administrator of ARROW@TU Dublin. For more information, please contact arrow.admin@tudublin.ie, aisling.coyne@tudublin.ie,gerard.connolly@tudublin.ie. Funder: Science Foundation Ireland}

Matthias, J. \& Ammann, M. (2007) Spline based geometry for printed UWB antenna design. IEEE Antennas and Propagation International Symposium, pp.761-764. Honolulu, 9-15 June, 2007, doi:10.1109/

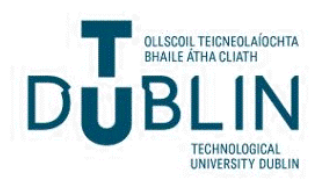




\title{
Spline Based Geometry for Printed UWB Antenna Design
}

\author{
Matthias John and Max J. Ammann \\ Centre for Telecommunications Value-Chain Research (CTVR) \\ School of Electronic \& Communications Engineering \\ Dublin Institute of Technology, Kevin Street, Dublin 8, Ireland \\ E-mail: matthias.john@student.dit.ie
}

\begin{abstract}
This paper presents a geometry for ultra-wideband (UWB) antennas which is based on quadratic Bézier spline curves. A genetic algorithm (GA) is used to optimise the geometry. The search space for the GA is minimised in order to improve the performance and computational efficiency of the algorithm. The optimised antenna covers the entire UWB bandwidth.
\end{abstract}

\section{Introduction}

The design of UWB antennas has received much attention in the research community in recent years. Most of these designs use canonical elements such as circles [1] or ellipses [2] for the radiating element. Combinations of these elements have also been used [3].

In this paper a geometry based on quadratic Bézier curves (splines) is proposed. The outline of the radiating element is described by few control points from which the shape is interpolated. This gives the radiating element an inherently rounded shape.

A genetic algorithm (GA) is used as an optimiser. GAs have been used to solve a variety of electromagnetic problems [4-5] including the design of printed monopole antennas [6]. The search space of the GA in this paper is minimised in order to keep the computational requirements small.

\section{Bézier Spline Geometry}

A quadratic Bézier spline is used to describe the outline of the radiating element. This curve is defined by 8 control points which are shown in Figure 1a. Two of these points are fixed, the other six are placed by the GA. The fixed points are $\mathrm{P}_{0}$ at $(0,0)$ and $\mathrm{P}_{4}$ at $(17,0)$. The antenna is fed at $\mathrm{P}_{0}$ by a $50 \Omega$ microstrip line. Points $\mathrm{P}_{1}-\mathrm{P}_{3}$ are defined by their $\mathrm{x}$ - and $\mathrm{y}$-coordinates. Points $\mathrm{P}_{5}-\mathrm{P}_{7}$ are copies of $\mathrm{P}_{1}-\mathrm{P}_{3}$ mirrored along the $\mathrm{x}$-axis. This enforces $\mathrm{X}$-axis symmetry in the radiating element, which is known to improve radiation patterns over asymmetrical radiating elements in the higher travelling wave modes [1].

For successful implementation the curve needs to be closed. To achieve this, 'virtual' points are generated in the middle between the control points, these are marked $\mathrm{P}_{\mathrm{v} n}$ in Figure 1a. A quadratic Bezier curve is now generated between each 
adjacent pair of these 'virtual' points with a control point between them. The expression defining this set of quadratic Bézier curves $B_{n}(t), n \in[0,7]$ is given by

$B_{n}(t)=(1-t)^{2} P_{v n}+2 t(1-t) P_{n}+t^{2} P_{v n+1} ; t \in[0,1], n \in[0,7]$

where $\mathrm{P}_{\mathrm{vn}}$ is the 'virtual' point before $\mathrm{P}_{\mathrm{n}}$ and $\mathrm{P}_{\mathrm{vn}+1}$ the point after $\mathrm{P}_{\mathrm{n}}$. In the case of $\mathrm{n}=7, \mathrm{P}_{\mathrm{vn}+1}$ is $\mathrm{P}_{\mathrm{v} 0}$. The resulting spline is smooth because the tangent on each $\mathrm{P}_{\mathrm{v} n}$ is the same for both curves that meet there.

\section{Genetic Algorithm Optimisation}

The positions of the control points $\mathrm{P}_{1}-\mathrm{P}_{3}, \mathrm{P}_{5}-\mathrm{P}_{7}$ is optimised by a genetic algorithm. The GA operates only on $\mathrm{P}_{1}-\mathrm{P}_{3}\left(\mathrm{P}_{5}-\mathrm{P}_{7}\right.$ are mirrored and not in the scope of the GA). The $\mathrm{x}$ - and $\mathrm{y}$-coordinate are encoded in binary format. Altogether these parameters can be encoded in 30 bit. Single point crossover and tournament selection are used. The mutation rate is $4 \%$.

The population size was set to 10 and evolved over 20 generations. Such small figures are possible because of the small search space of 30 bit. This keeps the computational requirements at a minimum. A laptop with a $\mathrm{P} 41.6 \mathrm{GHz}$ processor and $512 \mathrm{MB}$ ram solved this problem in 2 days. The GA was implemented in Perl [7] and CST Microwave Studio [8] was used with the FDTD solver.

The design goal is set to optimise for the widest possible bandwidth by summing up all frequency points at which the return loss is better than $-10 \mathrm{~dB}$. The fitness function is

$$
\text { fitness }=\sum_{n=0}^{1000}\left(S^{11}(n) \leq-10 d B\right) \text {. }
$$

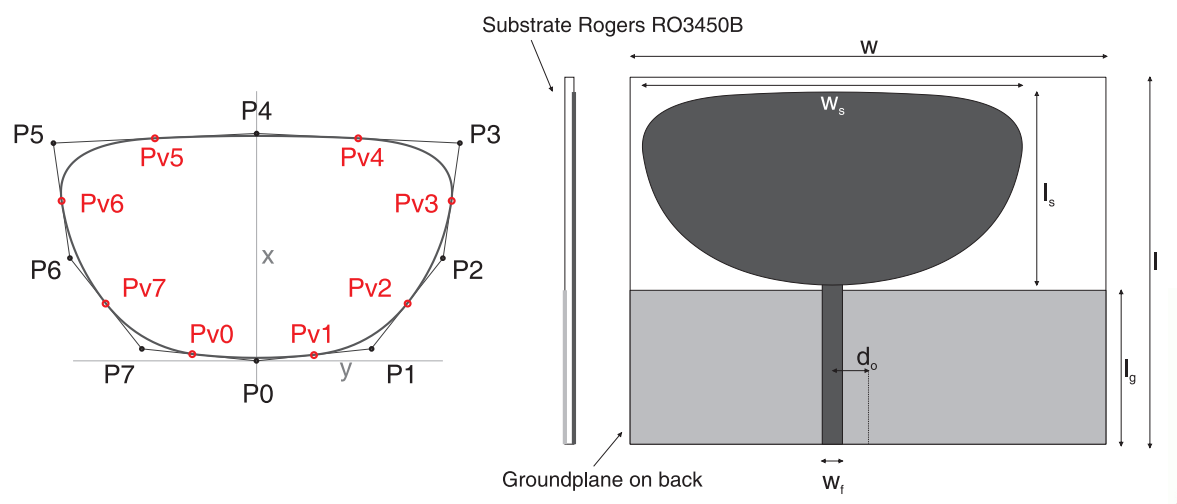

a

b

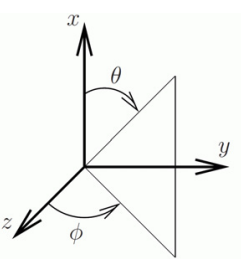

Figure 1. (a) Bézier spline outline and its control points, (b) Optimised geometry of the spline based UWB antenna. 


\section{Antenna Geometry}

The final geometry is shown in Figure 1b. The antenna was printed on Rogers microwave laminate PO4350B of $0.762 \mathrm{~mm}$ thickness, $\varepsilon_{\mathrm{r}}=3.48$ and $\tan \delta=0.0037$. The substrate has a size of $\mathrm{w}=40 \mathrm{~mm}$ by $\mathrm{l}=31 \mathrm{~mm}$. The radiating element and feed line are printed on one side, the groundplane on the other. The dimension of the groundplane is $\mathrm{w}=40 \mathrm{~mm}$ by $l_{\mathrm{g}}=13 \mathrm{~mm}$. The antenna is fed by a $\mathrm{w}_{\mathrm{f}}=1.7 \mathrm{~mm}$ microstrip feed line. The dimension of the spline based radiating element are $\mathrm{w}_{\mathrm{s}}=32 \mathrm{~mm}$ by $\mathrm{l}_{\mathrm{s}}=16.5 \mathrm{~mm}$.

The radiating element and feedline are offset by $d_{0}=3 \mathrm{~mm}$. Simulation has shown that by introducing this offset, the lower edge frequency is reduced by $180 \mathrm{MHz}$ from $3.26 \mathrm{GHz}$ to $3.08 \mathrm{GHz}$. Without increasing the substrate or groundplane size, the offset is necessary to achieve the ultra-wide bandwidth requirements.

\section{Results}

The simulated and measured return loss is shown in Figure 2. It can be seen that the measured return loss is greater then $10 \mathrm{~dB}$ from $2.92 \mathrm{GHz}$ to $14.9 \mathrm{GHz}$. The impedance bandwidth ratio is 5.1:1. Measured radiation patterns are shown in Figure 3. The H-plane patterns are omnidirectional except for very high frequencies. The E-plane patterns show typical monopole-like behaviour at low frequencies. The distortions at high frequencies are due to the offset.

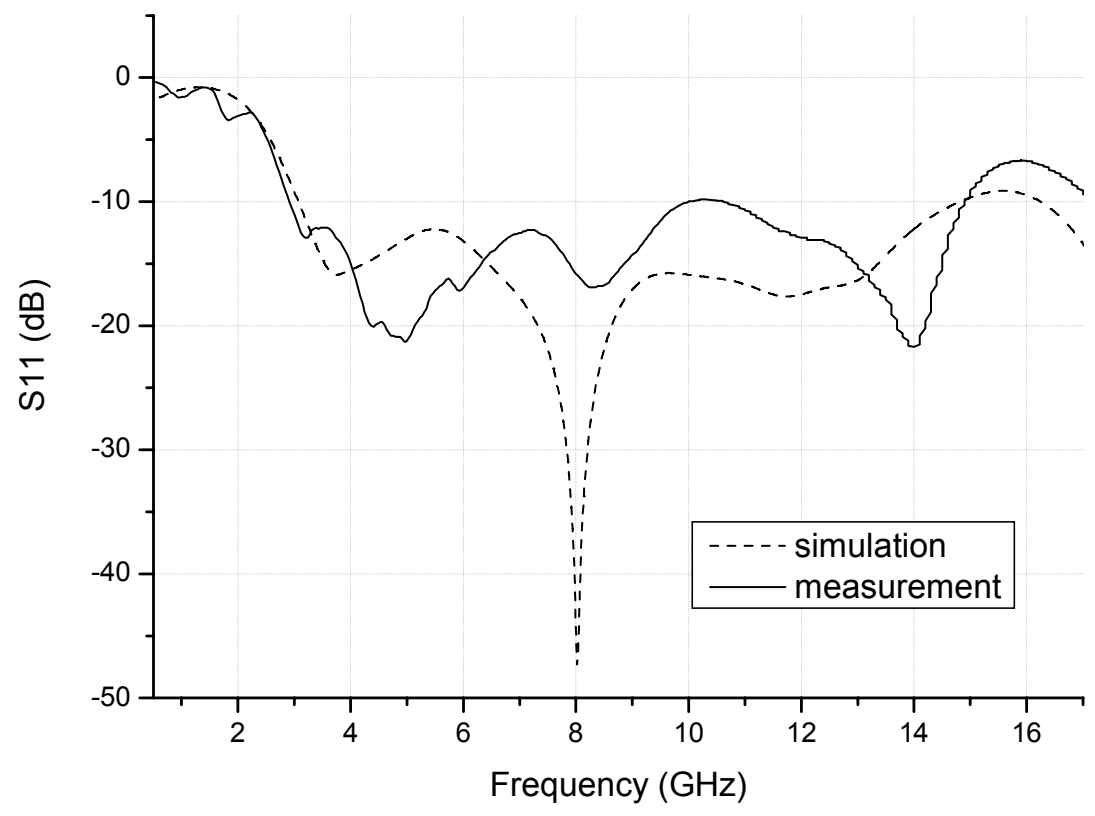

Fig. 2: Measured and simulated return loss of the spline UWB monopole. 

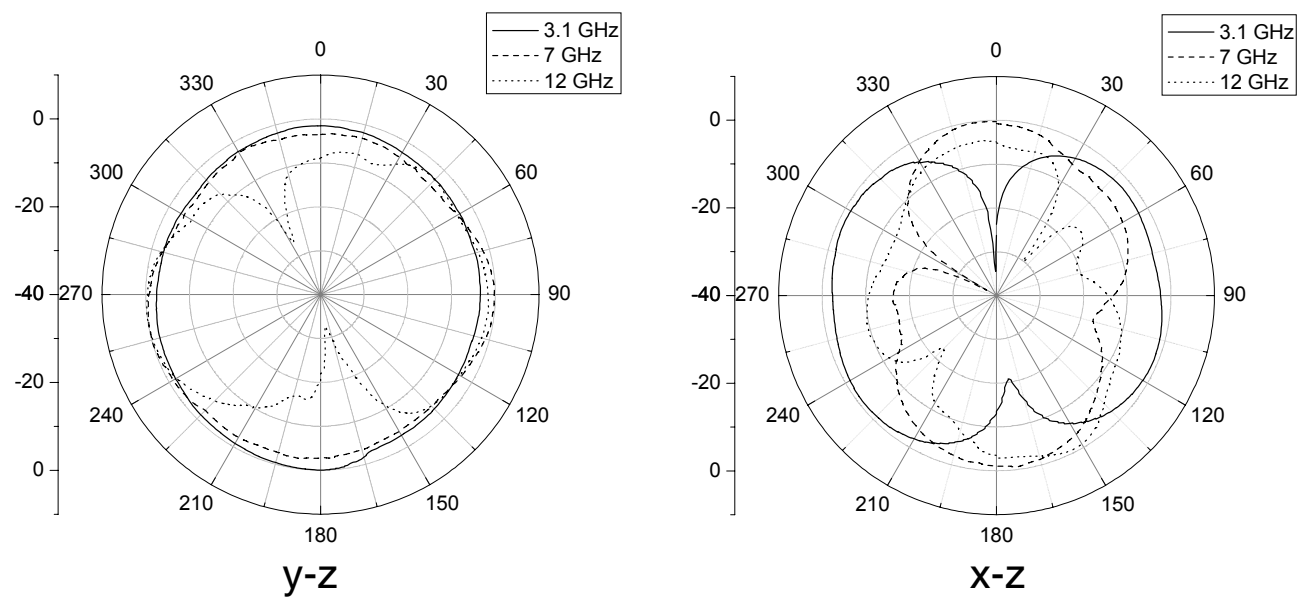

Fig. 3: Measured radiation patterns at $3.1 \mathrm{GHz}, 7 \mathrm{GHz}$ and $12 \mathrm{GHz}$ for the $\mathrm{y}-\mathrm{z}$ and $\mathrm{x}-\mathrm{z}$ planes.

\section{Conclusions}

A Bézier spline based UWB printed monopole antenna was presented. The geometry was optimised by a genetic algorithm. Three points are used to control the geometry. This allows for a small search space of only 30 bit for the GA. It was shown that this technique can give an impedance bandwidth ratio greater than 5:1 covering the entire UWB bandwidth. The small size of the antenna allows for easy integration into mobile UWB devices.

Acknowledgements: This work is supported by Science Foundation Ireland.

\section{References:}

[1] J. Liang, C.C. Chiau, X. Chen and C.G. Parini, "Study of a printed circular disk monopole antenna for UWB systems," IEEE Trans. Antennas \& Propag., vol. 53(11), pp. 3500-3504, Nov. 2005

[2] E.S. Angelopoulos, A.Z. Anastopoulos, D.I. Kaklamani, A.A. Alexandridis, F. Lazarakis and K. Dangakis, "Circular and elliptical CPW-fed slot and microstrip-fed antennas for ultrawideband applications," IEEE Antennas Wireless Propag. Lett., vol. 5, pp. 294-297, 2006.

[3] Z.N. Chen, M.J. Ammann, X. Qing, X.H. Wu, T.S.P. See and A. Cai, "Planar antennas: Promising solutions for microwave UWB applications," IEEE Microwave Magazine, vol. 7(6), pp. 63-73, Dec. 2006.

[4] R.L. Haupt, "An introduction to genetic algorithms for electromagnetics," IEEE Antennas \& Propag. Mag., vol. 37(2), pp. 7-15, Apr. 1995.

[5] J.M. Johnson and Y. Rahmat-Samii, "Genetic algorithms in engineering electromagnetics," IEEE Antennas \& Propag. Mag., vol. 39(4), pp. 7-21, Aug. 1997.

[6] L.A. Griffiths, C. Furse and Y.C. Chung, "Broadband and Multiband Antenna Design Using the Genetic Algorithm to Create Amorphous Shapes Using Ellipses," IEEE Trans. Antennas \& Propag., vol. 54(10), pp. 2776-2782, Oct. 2005.

[7] The Perl Foundation, The Perl Directory. [Online]. Available: http://www.perl.org/

[8] CST Microwave Studio. [Online]. Available: http://www.cst.com/ 